\title{
Reliability of Periapical Radiographs and Orthopantomograms in Detection of Tooth Root Protrusion in the Maxillary Sinus: Correlation Results with Cone Beam Computed Tomography
}

\author{
Bassam A. Hassan \\ Department of Oral Radiology, Academic Centre for Dentistry Amsterdam (ACTA), Amsterdam, Netherlands
}

\author{
Corresponding Author: \\ Bassam Hassan \\ Department of Oral Radiology, \\ Academic Centre for Dentistry Amsterdam (ACTA) \\ Louwesweg 1 \\ NL-1066 EA, Amsterdam \\ Netherlands \\ Phone: +31-(0)20-5188561 \\ Fax: +31-(0)20-5188480 \\ E-mail: b.hassan@acta.nl
}

\begin{abstract}
Objectives: The purpose of the present study was to investigate the reliability of both periapical radiographs and orthopantomograms for exact detection of tooth root protrusion in the maxillary sinus by correlating the results with cone beam computed tomography.

Material and methods: A database of 1400 patients scanned with cone beam computed tomography (CBCT) was searched for matching periapical (PA) radiographs and orthopantogram (OPG) images of maxillary premolars and molars. Matching OPG images datasets of 101 patients with 628 teeth and PA radiographs datasets of 93 patients with 359 teeth were identified. Four observers assessed the relationship between the apex of tooth root and the maxillary sinus per tooth on PA radiographs, OPG and $\mathrm{CBCT}$ images using the following classification: root tip is in the sinus (class 1), root tip is against the sinus wall (class 2) and root tip is not in the sinus (class 3 ).

Results: Overall correlation between OPG and CBCT images scores was 50\%, 26\% and 56.1\% for class 1, class 2 and class 3 , respectively (Cohen's kappa [weighted] $=0.1$ ). Overall correlation between PA radiographs and CBCT images was $75.8 \%$, $15.8 \%$ and $56.9 \%$ for class 1 , class 2 and class 3 , respectively (Cohen's kappa [weighted] $=0.24$ ). In both the OPG images and the PA radiographs datasets, class 1 correlation was most frequently observed with the first and second molars.

Conclusions: The results demonstrated that both periapical radiographs and orthopantomograms are not reliable in determination of exact relationship between the apex of tooth root and the maxillary sinus floor. Periapical radiography is slightly more reliable than orthopantomography in determining this relationship.
\end{abstract}

Keywords: dental radiography; cone-beam computed tomography; orthopantomography; tooth root; maxillary sinus.

Accepted for publication: 15 December 2009

To cite this article:

Bassam H. Reliability of Periapical Radiographs and Orthopantomograms in Detection of Tooth Root Protrusion in the Maxillary Sinus: Correlation Results with Cone Beam Computed Tomography.

J Oral Maxillofac Res 2010 (Jan-Mar);1(1):e6

URL: http://www.ejomr.org/JOMR/archives/2010/1/e6/e6ht.htm

doi:10.5037/jomr.2010.1106 


\section{INTRODUCTION}

Exact assessment of the relationship between roots of maxillary premolars and molars and inferior wall of the maxillary sinus is essential in oral and maxillofacial pathology diagnosis. There are namely many important clinical implications for protrusion of roots in the maxillary sinus. For example, tooth extraction or endodontic surgery can lead to the formation of an oroantral fistula or oroantral communication in a case of presenting tooth root protrusion in the maxillary sinus [1]. Furthermore, the maxillary sinus has been found to be the most significant pathway of periapical infection spreading for maxillary first and second premolars [2-5]. In addition, increased pneumatization of the maxillary sinus and decreased alveolar bone thickness can often be observed after extraction of premolars and molars, which complicates implant placement $[\underline{6}, \underline{7}]$. Spread of periapical infection from maxillary molars to surrounding structures was previously demonstrated on computed tomography (CT) images [2]. The influence of root protrusion in the maxillary sinus floor may evoke tooth roots resorption or tipping during orthodontic treatment $[\underline{8}, 9]$.

The maxillary tooth root and sinus relationship can be assessed using different radiographic techniques. Conventional radiographs used in dental clinics include mainly intraoral periapical (PA) radiographs and to a lesser extent orthopantomograms (OPG). Virtually every radiographic examination in the dental clinic starts with a PA radiograph. In contrast, it has been shown in surveys, that up to $95 \%$ of dentists refer their patients solely for an OPG scan before implant placement with only a relatively small number of referrals for a CT scan $[\underline{10}, \underline{11}]$. It is interesting to know, that several studies assessed the vertical and horizontal relationship between the tooth root apex and the inferior wall of the maxillary sinus using CT diagnostic method [12-16]. It was concluded that CT is more accurate than OPG in assessing the tooth root and sinus relationship [17]. Anyhow, two-dimensional radiographs suffer from superimposition artifacts inherent to the scan method frequently resulting in overprojection of maxillary teeth roots onto the sinus floor. Authors of two studies correlating $\mathrm{CT}$ scans and OPG images findings confirmed that OPG alone is unreliable in assessing the relationship between the teeth roots and the maxillary sinus [17-18]. Similarly the reliability of PA radiographs in detection of root penetration in the maxillary sinus also needs further investigations [19]. Otherwise, cone beam computed tomography (CBCT) scanning technology, which has been in wide use in dentistry for the last decade, is advantageous over traditional CT scanning technology since it provides comparable images at reduced dose and cost $[20,21]$. $\mathrm{CBCT}$ proved to be a reliable technique for visualizing anatomical structures in the maxillofacial region and for assessing the relationship of teeth roots to adjacent structures including the maxillary sinus [22-25].

The purpose of the present study was to investigate the reliability of both periapical radiographs and orthopantograms for exact detection of tooth root protrusion in the maxillary sinus by correlating the results with cone beam computed tomography as a reference "gold standard".

\section{MATERIAL AND METHODS}

\section{Data collection}

In this retrospective study the database of patients scanned with CBCT at the Department of Oral Radiology, University of Amsterdam was examined. The initial selection criteria were: patients older than 18 years and the presence of one or multiple posterior maxillary teeth with a fully visible inferior maxillary sinus wall. Initial screening with these criteria resulted in the inclusion of 1400 CBCT patient's images. The images were made with the NewTom 3G CBCT system (QR SLR, Verona, Italy) using the 9" field of view (FoV) selection and $110 \mathrm{kVp}$ and $8 \mathrm{~mA}$. Subsequently, the patients' records database was searched for matching conventional OPG images and intraoral PA radiaographs. Only those OPG images and PA radiographs were included in the study, where the relationship of teeth roots to the maxillary sinus floor could be adequately assessed. First, a dataset of matching OPG images of 101 patients (33 males and 68 females; aged 18 to 77 years; mean age $=49$ years) with 628 maxillary premolars and molars was obtained. A second dataset of matching PA radiographs of 93 patients ( 37 males and 56 females; aged 23 to 74 years; mean age $=51$ years) with 359 maxillary premolars and molars was also identified and included in this study. The OPG images were performed using the Cranex Tome unit (Soredex, Tuusula, Finland) and the PA radiographs using a fixed intraoral unit (Heliodent MD, Siemens, Erlangen, Germany) and size 2 phosphorplate films (Digora, Tuusula, Finland).

\section{Data analysis}

Four dentists following a master course in maxillofacial radiology at the Department of Oral Radiology were recruited as observers for this study. The datasets were collected by one investigator (maxillofacial radiologist, Department of Oral Radiology, University 


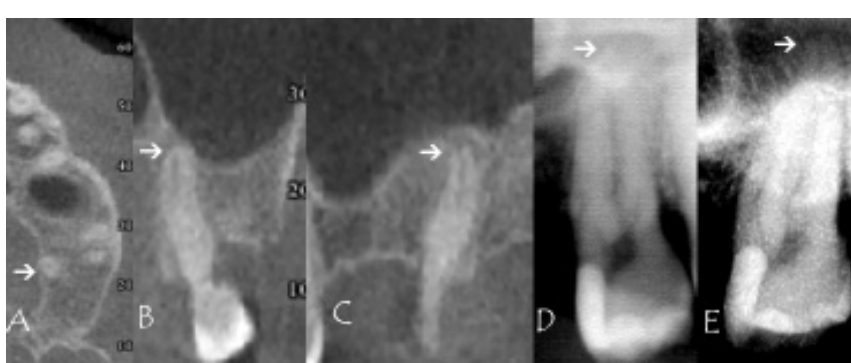

Figure 1. An example of no protrusion of tooth \#27 palatal root tip (arrow) in the maxillary sinus according to cone beam computed tomography scans assessment: $\mathrm{A}=$ axial slice; $\mathrm{B}=$ coronal slice; $\mathrm{C}=$ sagittal slice. Tooth root $\# 27$ overprojection onto the maxillary sinus floor using orthopantomogram images (D) and periapical radiographs $(\mathrm{E})$.

of Amsterdam) who did not participate in the observations. The observers were blinded to the patients' biographic data including name, gender and age. The observers were calibrated by training them in the radiographic features for identifying the relationship of the teeth roots to the inferior wall of the maxillary sinus. The identifying radiographic feature in all imaging modalities was to assess whether the apical root tip of right and left first and second premolars, first, second and third molars is over (in), against (doubtful) or under (out) the white line depicting the inferior border of the maxillary sinus. The observers assessed first the conventional PA radiographs and OPG and then the CBCT images. All measurements were made with consensus among the four observers. Radiographs were displayed under standardized lightening conditions of reduced dim light on a 21-inch flat-panel screen (resolution 1680 x 1050, Philips Brilliance, Amsterdam, Netherlands). The PA radiographs and OPG images were displayed using Emago imaging software (v.5.4, Amsterdam, Netherlands) (Figure 1). The CBCT images datasets were reviewed using the NewTom $3 \mathrm{G}$ software (v.2.17, Verona, Italy). Multiplanar reformatted reconstructions in the axial, coronal and sagittal planes were created and the relationship of the teeth root tip

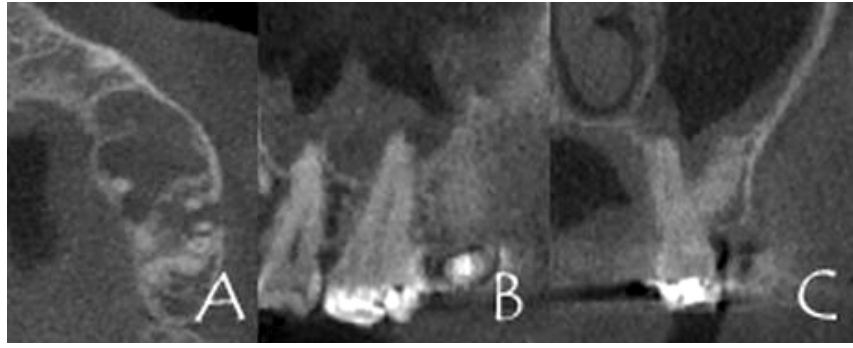

Figure 2. An example of tooth \#26 palatal root protrusion in the maxillary sinus according to cone beam computed tomography scans multiplanar reformatted images: $\mathrm{A}=$ axial slice; $\mathrm{B}=$ sagittal slice; $\mathrm{C}=$ coronal slice.

to the maxillary floor was assessed in all three reconstruction planes on all slices (Figure 2). Voxel size in CBCT images were $0.3 \mathrm{~mm}$ with no inter-slice thickness (contiguous dataset). Image manipulation by changing contrast/brightness levels, sharpness filter and magnification was permitted to enhance visibility.

A single score was obtained for each tooth whether single or multirooted for each imaging technique with the following classification: at least one root tip is in the sinus (class 1); at least one root tip is against the sinus wall (class 2) and all roots tips are not in the sinus (class 3).

\section{Statistical analysis}

All measurements were entered and analyzed using SPSS software (v.16, SPSS Benelux, Gorinchem, Netherlands). A two-sided Chi square test and Cohen's weighted kappa coefficient were used to correlate the OPG images and PA radiographs measurements with the CBCT assessment scores. A univariate analysis of variance (ANOVA) was also conducted to assess any possible correlation between the proportion of presence of root in the sinus and patients' age and sex. Differences were considered as statistically significant when $\mathrm{P}$ values were $<0.05$.

Table 1. Classification ${ }^{\mathrm{a}}$ of maxillary premolars and molars roots relationship to the maxillary sinus floor according to cone beam computed tomography scans and orthopantomogram images assessment results

\begin{tabular}{|c|c|c|c|c|c|c|c|c|c|c|c|c|c|c|}
\hline \multirow[t]{2}{*}{ Maxillary teeth } & \multirow[t]{2}{*}{$\mathbf{N}$} & \multicolumn{3}{|c|}{$\begin{array}{c}\text { Cone beam computed } \\
\text { tomography } \\
(\mathrm{n}[\%])\end{array}$} & \multicolumn{3}{|c|}{$\begin{array}{l}\text { Orthopantomography } \\
\text { (n [\%]) }\end{array}$} & \multirow{2}{*}{ 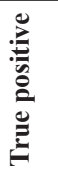 } & \multirow{2}{*}{ 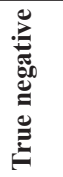 } & \multirow{2}{*}{ 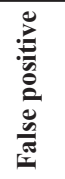 } & \multirow{2}{*}{ 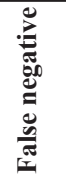 } & \multirow{2}{*}{$\sum_{\substack{0 \\
:}}$} & \multirow{2}{*}{ 竞 } & \multirow{2}{*}{ 这 } \\
\hline & & Class 1 & Class 2 & Class 3 & Class 1 & Class 2 & Class 3 & & & & & & & \\
\hline First premolar & 148 & 0 & $1(0.7)$ & 147 (99.3) & $32(21.6)$ & $24(16.2)$ & $92(62.2)$ & 0 & 62.2 & 21.8 & 0 & 0 & 74 & 0.01 \\
\hline Second premolar & 146 & $2(1.4)$ & $6(4.1)$ & $138(94.5)$ & $40(27.4)$ & $21(14.4)$ & $85(58.2)$ & 100 & 60 & 24.6 & 0 & 100 & 70 & 0.05 \\
\hline Second molar & 145 & $26(17.9)$ & $25(17.2)$ & $94(64.8)$ & $51(35.2)$ & $29(20)$ & $65(44.8)$ & 57.7 & 50 & 33 & 26.9 & 68 & 60 & 0.16 \\
\hline Third molar & 45 & $6(13.3)$ & $1(2.2)$ & $38(84.4)$ & $13(28.9)$ & $9(20)$ & $23(51.1)$ & 50 & 51.1 & 26.3 & 50 & 50 & 66 & 0.11 \\
\hline Total (n [\%]) & $628(100)$ & $68(10.8)$ & $50(8)$ & $510(81.2)$ & $187(29.8)$ & 108 (17.2) & $333(53)$ & & & & & & & 0.1 \\
\hline
\end{tabular}

${ }^{\text {a }}$ Class $1=$ at least one root tip is in the sinus; Class $2=$ at least one root tip is against the sinus wall; Class $3=$ all roots tips are not in the sinus. 
Table 2. Classification ${ }^{\mathrm{a}}$ of maxillary premolars and molars roots relationship to the maxillary sinus floor according to cone beam computed tomography scans and periapical radiographs assessment results

\begin{tabular}{|c|c|c|c|c|c|c|c|c|c|c|c|c|c|c|}
\hline \multirow[t]{2}{*}{ Maxillary teeth } & \multirow[t]{2}{*}{$\mathbf{N}$} & \multicolumn{3}{|c|}{$\begin{array}{l}\text { Cone beam computed tomography } \\
(\mathrm{n}[\%])\end{array}$} & \multicolumn{3}{|c|}{$\begin{array}{l}\text { Periapical radiography } \\
\text { (n [\%]) }\end{array}$} & \multirow{2}{*}{ 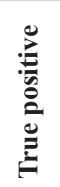 } & \multirow{2}{*}{ 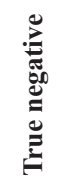 } & \multirow{2}{*}{ 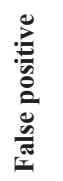 } & \multirow{2}{*}{ 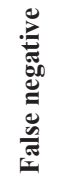 } & \multirow{2}{*}{ 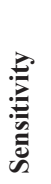 } & \multirow{2}{*}{ 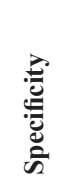 } & \multirow{2}{*}{ 苛 } \\
\hline & & Class 1 & Class 2 & Class 3 & Class 1 & Class 2 & Class 3 & & & & & & & \\
\hline First premolar & 90 & $3(3.3)$ & $1(1.1)$ & 86 (95.6) & $8(8.9$ & $7(7.8)$ & 75 (83.3) & 0 & 84.9 & 8.1 & 66.7 & 0 & 91 & 0.05 \\
\hline Second premolar & 88 & $8(9.1)$ & $8(9.1)$ & $72(81.8)$ & $17(19.3)$ & $19(21.6)$ & $52(59.1)$ & 25 & 63.9 & 16.7 & 50 & 59 & 79 & 0.12 \\
\hline First molar & 90 & $28(31.1)$ & $6(6.7)$ & $56(62.2)$ & $71(78.9)$ & $2(2.2)$ & $17(18.9)$ & 92.9 & 28.6 & 69.6 & 3.6 & 96 & 29 & 0.16 \\
\hline Second molar & 83 & $27(32.5)$ & $4(4.8)$ & $52(62.7)$ & $59(71.1)$ & $4(4.8)$ & $20(24.1)$ & 81.5 & 32.7 & 63.5 & 11.1 & 88 & 33 & 0.13 \\
\hline Total (n [\%]) & $359(100)$ & 66 (18.4) & $19(5.3)$ & $266(76.3)$ & $155(44.3)$ & $32(8.9)$ & $164(46.8)$ & & & & & & & 0.24 \\
\hline
\end{tabular}

${ }^{\mathrm{a}}$ Class $1=$ at least one root tip is in the sinus; Class $2=$ at least one root tip is against the sinus wall; Class $3=$ all roots tips are not in the sinus.

\section{RESULTS}

In the assessment of 628 teeth included in the OPG images dataset (Table 1), sixty eighth teeth $(10.8 \%)$ were identified as class $1,50(8 \%)$ class 2 and 510 $(81.2 \%)$ class 3 . Within the 359 teeth included in the PA radiographs dataset (Table 2), sixty six teeth $(18.4 \%)$ were identified as class 1,19 (5.3\%) class 2 and 266 (76.3\%) class 3 . Table 1 shows the classifications, proportions, sensitivity, specificity and Cohen's weighted kappa coefficient results between (OPG) images and CBCT scans for protrusion of roots in the maxillary sinus per tooth. Overall correlation between OPG and CBCT assessments scores independently of tooth type was $50 \%, 26 \%$ and $56.1 \%$ for class 1 , class 2 and class 3, respectively (Cohen's kappa [weighted] $=0.1$ ). Overall correlation between PA radiography and CBCT assessments scores (Table 2) independently of tooth type was $75.8 \%, 15.8 \%$ and $56.9 \%$ for class 1 , class 2 and class 3, respectively (Cohen's kappa $[$ weighted $]=0.24)$. There was no statistically significant correlation between the proportion of root protrusion in the maxillary sinus and age $(\mathrm{P}=0.32)$ or $\operatorname{sex}(\mathrm{P}=0.40)$ in both datasets.

In both PA radiographs and OPG images datasets, class 1 relationship in which the root penetrated the sinus wall was most frequently observed with the first and second molars (Tables 1 and 2). Class 2 relationship in which the root was against the sinus wall, was observed in a relatively small number of cases and was also most frequently associated with the first and second molars. The majority of the other cases were identified as class 3 in which there were no contact between the root and the sinus floor and this was most frequently observed with the first premolar (Tables 1 and 2).

\section{DISCUSSION}

The present investigation was conducted to assess the reliability of PA and OPG radiographs in detection of tooth root protrusion of the maxillary sinus inferior wall. The correlation results with CBCT measurements, per tooth and overall, demonstrated low reliability of both OPG scans and PA radiographs for detection of tooth root protrusion (Tables 1 and 2). Due to the superimposition of anatomical structures on conventional two-dimensional radiographs, the roots of the premolars and molars were overprojected on the wall of the maxillary sinus. There was better correlation between CBCT scans and PA radiographs scores than between CBCT scans and OPG images scores. This may be due to the use of paralleling technique for intraoral radiographs with the aid of a film holder and a beam indicating device that both the film and the long axis of the root were parallel to each other with the X-ray beam passing perpendicularly to both root and film [26]. It is noteworthy that a standardized paralleling technique is routinely used in our institute unless a contraindication favors the use of the bisecting angle technique instead. Therefore, the results could differ somewhat from private dental clinics.

The present study results revealed, independently on applied radiographic method, that the maxillary first premolar tooth did not perforate the sinus wall in most cases while first and second molars were the most frequent teeth to penetrate the maxillary sinus wall (Tables 1 and 2). This is in agreement with previous findings $[16,18]$. There were many false positives in both techniques. The largest number of false positives was with the maxillary second molar (33\%) for OPG while it was the first molar $(69.6 \%)$ for PA. It was previously found that the least thickness of the sinus floor is at the maxillary second molar area and that the average distance of the root apex from the sinus floor was the longest in the first premolar area and 
shortest in the second molar area $[15,27]$.

Several classifications for the relationship of the teeth to the maxillary sinus floor were previously suggested. Freisfeld et al. [28] suggested a classification applicable for both panoramic images and CT scans based on the first molar. Kwak et al. [16] suggested an elaborate classification for the vertical relationship of the tooth root apex on CT scans and the results were compared to histological findings. They found that the inferior wall of the sinus was located above the level connecting the buccal and lingual roots apices in the first and second molars region in $54.5 \%$ and $52.4 \%$ of cases respectively. Sharan et al. [18] extended Freisfeld's et al. [28] classification and made this applicable to both OPG images and CT scans. The classification used in present study was a reduced version of that of Sharan et al. [18] classification. Sharan et al. [18] found that in 80 subjects with 422 maxillary roots, there was high agreement of $86 \%$ to $96 \%$ between CT scans and OPG images for roots that did not project on the sinus floor. While only $39 \%$ of the roots that projected on the sinus cavity in OPG images showed protrusion into the sinus on CT scans. Their results also demonstrate that OPG images cannot provide the clinician with sufficient information about the true relationship between the sinus floor and root tips when the root is projected on the sinus. The results of this study corroborate those findings and additionally suggest that PA radiography could be a more reliable technique than OPG in detecting root protrusion in the sinus.

Present study was limited that two separate databases where employed to assess the accuracy of OPG and PA radiography. A common database with a sufficient sample size for statistical analysis in which the patient has matching CBCT, OPG and PA radiographs could not be identified. CBCT was used in this study as a "gold standard" since the tomographic nature and inherently high image contrast of this imaging modality compared to conventional projection radiography permits better assessment of the relationship between the root apex and the sinus wall. However, CBCT image artifacts and increased noise levels might occasionally mask the root and the sinus wall rendering precise assessment difficult. The reliably of the "reference standard" is thus limited by the spatial resolution and contrast of the system used. Additionally, this study focused mainly on the vertical relation of the root to the maxillary sinus and the horizontal relationship was not assessed.

\section{CONCLUSIONS}

The results of present study demonstrated that both periapical radiographs and orthopantomograms were not reliable in determination of exact relationship between the apex of tooth root and the maxillary sinus floor. Periapical radiographs were slightly more reliable than orthopantomograms in determining this relationship.

\section{ACKNOWLEDGMENTS AND DISCLOSURE STATEMENTS}

The author would like to thank Dr. Jamshed Tairie, Department of Oral Radiology, Academic Centre for Dentistry Amsterdam (ACTA), for his support with data analysis and Dr. Hans Verheij, Department of Oral Radiology, Academic Centre for Dentistry Amsterdam (ACTA), for his support with the statistical analysis.

The author declares that there is no conflict of interest of any kind in this study.

\section{REFERENCES}

1. Harrison DF. Oro-antral fistula. Br J Clin Pract. 1961 Feb;15:169-74. [Medline: 13711812]

2. Obayashi N, Ariji Y, Goto M, Izumi M, Naitoh M, Kurita K, Shimozato K, Ariji E. Spread of odontogenic infection originating in the maxillary teeth: computerized tomographic assessment. Oral Surg Oral Med Oral Pathol Oral Radiol Endod. 2004 Aug;98(2):223-31. [Medline: 15316549] [doi: 10.1016/j.tripleo.2004.05.014]

3. Yoshiura K, Ban S, Hijiya T, Yuasa K, Miwa K, Ariji E, Tabata O, Araki K, Tanaka T, Yonetsu K, et al. Analysis of maxillary sinusitis using computed tomography. Dentomaxillofac Radiol. 1993 May;22(2):86-92. [Medline: 8375560]

4. Kretzschmar DP, Kretzschmar JL. Rhinosinusitis: review from a dental perspective. Oral Surg Oral Med Oral Pathol Oral Radiol Endod. 2003 Aug;96(2):128-35. Review. [Medline: 12931083] [doi: 10.1016/S1079-2104(03)00306-8]

5. Kamijyo T. Clinical osteology. In: Kamijyo T, editor. Oral anatomy. Vol 1: osteology. Tokyo: Anatom: 1997; p. 207-216.

6. Kircos LT, Misch CE. Diagnostic imaging and techniques. In: Misch CE, editor. Contemporary implant dentistry. 2nd ed. St. Louis: Mosby: 1999; p. 76-194.

7. Wehrbein H, Diedrich P. [Progressive pneumatization of the basal maxillary sinus after extraction and space closure]. Fortschr Kieferorthop. 1992 Apr;53(2):77-83. German. [Medline: 1577348]

8. Daimaruya T, Takahashi I, Nagasaka H, Umemori M, Sugawara J, Mitani H. Effects of maxillary molar intrusion on the nasal floor and tooth root using the skeletal anchorage system in dogs. Angle Orthod. 2003 Apr;73(2):158-66. [Medline: 12725372] 
9. Wehrbein H, Bauer W, Wessing G, Diedrich P. [The effect of the maxillary sinus floor on orthodontic tooth movement]. Fortschr Kieferorthop. 1990 Dec;51(6):345-51. German. [Medline: 2286348]

10. Sakakura CE, Morais JA, Loffredo LC, Scaf G. A survey of radiographic prescription in dental implant assessment. Dentomaxillofac Radiol. 2003 Nov;32(6):397-400. [Medline: 15070843 ] [doi: 10.1259/dmfr/20681066]

11. Beason RC, Brooks SL. Preoperative implant site assessment in southeast Michigan. J Dent Res 2001;80:136.

12. Bertrand B, Rombaux P, Eloy P, Reychler H. Sinusitis of dental origin. Acta Otorhinolaryngol Belg. 1997;51(4):315-22. Review. [Medline: 9444378 ]

13. Ariji E, Moriguchi S, Kuroki T, Kanda S. Computed tomography of maxillofacial infection. Dentomaxillofac Radiol. 1991 Aug;20(3):147-51. [Medline: 1807998]

14. Ariji Y, Obayashi N, Goto M, Izumi M, Naitoh M, Kurita K, Shimozato K, Ariji E. Roots of the maxillary first and second molars in horizontal relation to alveolar cortical plates and maxillary sinus: computed tomography assessment for infection spread. Clin Oral Investig. 2006 Mar;10(1):35-41. Epub 2005 Dec 15. [Medline: 16362431] [doi: 10.1007/s00784-005-0020-5]

15. Eberhardt JA, Torabinejad M, Christiansen EL. A computed tomographic study of the distances between the maxillary sinus floor and the apices of the maxillary posterior teeth. Oral Surg Oral Med Oral Pathol. 1992 Mar;73(3):345-6. [Medline: 1545967]

16. Kwak HH, Park HD, Yoon HR, Kang MK, Koh KS, Kim HJ. Topographic anatomy of the inferior wall of the maxillary sinus in Koreans. Int J Oral Maxillofac Surg. 2004 Jun;33(4):382-8. [Medline: 15145042] [doi: 10.1016/j.ijom.2003.10.012]

17. Bouquet A, Coudert JL, Bourgeois D, Mazoyer JF, Bossard D. Contributions of reformatted computed tomography and panoramic radiography in the localization of third molars relative to the maxillary sinus. Oral Surg Oral Med Oral Pathol Oral Radiol Endod. 2004 Sep;98(3):342-7. [Medline: 15356474] [doi: 10.1016/j.tripleo.2004.02.082]

18. Sharan A, Madjar D. Correlation between maxillary sinus floor topography and related root position of posterior teeth using panoramic and cross-sectional computed tomography imaging. Oral Surg Oral Med Oral Pathol Oral Radiol Endod. 2006 Sep;102(3):375-81. Epub 2006 Jun 8. [Medline: 16920546] [doi: 10.1016/j.tripleo.2005.09.031]

19. Low KM, Dula K, Bürgin W, von Arx T. Comparison of periapical radiography and limited cone-beam tomography in posterior maxillary teeth referred for apical surgery. J Endod. 2008 May;34(5):557-62. [Medline: 18436034] [doi: 10.1016/i.joen.2008.02.022]

20. Loubele M, Bogaerts R, Van Dijck E, Pauwels R, Vanheusden S, Suetens P, Marchal G, Sanderink G, Jacobs R. Comparison between effective radiation dose of CBCT and MSCT scanners for dentomaxillofacial applications. Eur J Radiol. 2009 Sep;71(3):461-8. Epub 2008 Jul 18. [Medline: 18639404] [doi: 10.1016/j.ejrad.2008.06.002]

21. Tsiklakis K, Donta C, Gavala S, Karayianni K, Kamenopoulou V, Hourdakis CJ. Dose reduction in maxillofacial imaging using low dose Cone Beam CT. Eur J Radiol. 2005 Dec;56(3):413-7. Epub 2005 Jun 22. [Medline: 15978765] [doi: 10.1016/j.ejrad.2005.05.011]

22. Tantanapornkul W, Okouchi K, Fujiwara Y, Yamashiro M, Maruoka Y, Ohbayashi N, Kurabayashi T. A comparative study of cone-beam computed tomography and conventional panoramic radiography in assessing the topographic relationship between the mandibular canal and impacted third molars. Oral Surg Oral Med Oral Pathol Oral Radiol Endod. 2007 Feb;103(2):253-9. Epub 2006 Sep 1. [Medline: 17234544] [doi: 10.1016/j.tripleo.2006.06.060]

23. Angelopoulos C, Thomas SL, Hechler S, Parissis N, Hlavacek M. Comparison between digital panoramic radiography and cone-beam computed tomography for the identification of the mandibular canal as part of presurgical dental implant assessment. J Oral Maxillofac Surg. 2008 Oct;66(10):2130-5. Erratum in: J Oral Maxillofac Surg. 2008 Dec;66(12):2657. Thomas, Stephen [corrected to Thomas, Steven L]; Hechler, Stephen [corrected to Hechler, Steven]. [Medline: 18848113] [doi: 10.1016/j.joms.2008.06.021]

24. Neugebauer J, Shirani R, Mischkowski RA, Ritter L, Scheer M, Keeve E, Zöller JE. Comparison of cone-beam volumetric imaging and combined plain radiographs for localization of the mandibular canal before removal of impacted lower third molars. Oral Surg Oral Med Oral Pathol Oral Radiol Endod. 2008 May;105(5):633-42; discussion 643. Epub 2008 Mar 4. [Medline: 18299225] [doi: 10.1016/j.tripleo.2007.08.041]

25. Sawamura T, Minowa K, Nakamura M. Impacted teeth in the maxilla: usefulness of 3D Dental-CT for preoperative evaluation. Eur J Radiol. 2003 Sep;47(3):221-6. [Medline: 12927666] [doi: 10.1016/S0720-048X(02)00168-7]

26. White SC, Pharoah MJ. Intraoral radiography. In: White SC, Pharoah MJ, editors. Oral radiology: principles and interpretation. 5th ed. St. Louis: Mosby: 2004; p. 77-90.

27. Mustian WF. The floor of the maxillary sinus and its dental and nasal relation. J Am Dent Assoc 1933: 20: 2175-2187.

28. Freisfeld M, Drescher D, Schellmann B, Schüller H. [The maxillary sixth-year molar and its relation to the maxillary sinus. A comparative study between the panoramic tomogram and the computed tomogram]. Fortschr Kieferorthop. 1993 Oct;54(5):179-86. German. [Medline: 8244214] 


\section{To cite this article:}

Bassam H. Reliability of Periapical Radiographs and Orthopantomograms in Detection of Tooth Root Protrusion in the Maxillary Sinus: Correlation Results with Cone Beam Computed Tomography.

J Oral Maxillofac Res 2010 (Jan-Mar);1(1):e6

URL: http://www.ejomr.org/JOMR/archives/2010/1/e6/e6ht.htm

doi: $10.5037 /$ jomr.2010.1106

Copyright (C) Bassam H. Accepted for publication in the JOURNAL OF ORAL \& MAXILLOFACIAL RESEARCH (http:// www.ejomr.org/), 15 December 2009.

This is an open-access article, first published in the JOURNAL OF ORAL \& MAXILLOFACIAL RESEARCH, distributed under the terms of the Creative Commons Attribution-Noncommercial-No Derivative Works 3.0 Unported License, which permits unrestricted non-commercial use, distribution, and reproduction in any medium, provided the original work and is properly cited. The copyright, license information and link to the original publication on (http://www.ejomr.org/) must be included. 